\title{
Domínio, migração e natureza na Amazônia seiscentista
}

\author{
Wesley Oliveira Kettle
}

CHAMBOULEYRON, Rafael. Povoamento, ocupação e agricultura na Amazônia colonial (1640-1706). Belém: Editora Açaí, 2010.

Ao longo do século XVII, no Estado do Brasil, a regiáo açucareira assumiu uma posição central, na medida em que se tratava, para a sobrevivência econômica do Estado Português, de uma atividade fundamental nos domínios ultramarinos. Nesse contexto, é possível considerar que a importância da Amazônia para Portugal foi determinada pela sua própria condição de pobreza? Em Povoamento, ocupação e agricultura na Amazônia colônia (1640-1706), Rafael Chambouleyron demonstra essa possibilidade. Segundo ele, o paradoxo é explicado pelo fato de que o atraso da Amazônia náo resultou em seu abandono; pelo contrário, provocou uma forte e constante intervenção da Coroa portuguesa. $\mathrm{O}$ autor parte da constataçáo de que a administraçáo metropolitana passou a promover o controle, incentivo e ordenamento de importantes áreas da dinâmica colonial, como o povoamento, a economia, as atividades comerciais e a reprodução da força de trabalho.

Para desenvolver sua argumentação, Rafael Chambouleyron, professor de História da Universidade Federal do Pará, toma como ponto de partida a advertência feita pelo Conselho Ultramarino, em consulta ao príncipe regente de Portugal, Dom Pedro II, no ano de 1673, na qual a Amazônia é descrita como uma regiáo bastante extensa, desabitada e sem atividade comercial. $\mathrm{O}$ autor se debruça entáo sobre a resposta que a Coroa Portuguesa deu a esses problemas apontados pelos conselheiros, promovendo a agricultura, a ocupaçáo e o povoamento do território.

Outra motivação, de natureza diferente, que conduz o trabalho de Chambouleyron é a constatação de que grande parte da historiografia brasileira e brasilianista, que procurou explicar a formaçáo colonial do Brasil, escolheu dar atenção às áreas "dinâmicas", deixando de lado a experiência da Amazônia seiscentista. $\mathrm{O}$ autor considera equivocado identificar a Amazônia olonial como área periférica, atribuindo esse entendimento a uma historiografia clássica que interpretou a experiência portuguesa na América, a partir de sua atuaçáo no Atlântico Sul e na regiáo açucareira - considerada modelar -, cobrando, assim, do Estado do Maranhão, o que lhe faltava em relação a esse modelo.

Demonstrando um cuidado primoroso no trato das fontes, Rafael Chambouleyron desenvolve uma história da Amazônia colonial "vista de dentro”, influenciado pelos estudos de Sérgio Buarque de Holanda, inspiração reconhecida pelo próprio autor. Vale ressaltar que sua rejeiçáo à dicotomia sertáo/litoral, como dois mundos desarticulados, procura, com sucesso, demonstrar que, na realidade, integram o mesmo universo. Debruça-se sobre a dinâmica colonial, sem deixar de lado a experiência imperial portuguesa, optando por compreender o conjunto das políticas da Coroa, a partir do contexto da Restauração.

A obra de Chambouleyron não apenas questiona as formulaçôes de historiadores clássicos, procurando dar atenção a uma conquista tratada como de importância secundária por parte da historiografia, como também analisa personagens que não aqueles "emblemáticos" do século XVII. Sua análise privilegia uma investigação que parte da atuação de "pequenos atores", membros do Conselho Ultramarino menos conhecidos, alguns inclusive anônimos, e dos indivíduos e grupos sociais atendidos por eles.

Ao contrário dos trabalhos de Anthony John Russell-Wood e João Francisco Lisboa, para quem a Coroa portuguesa não se interessava pela migração para a Amazônia, Chambouleyron, por meio de uma escrita cuidadosa que identifica as fontes históricas examinadas - sem que isso prejudique a fluência de sua narrativa -, revela 
uma ação intensa da Coroa no fluxo migratório para o Maranháo. No primeiro capítulo, "Povoadores, degredados e soldados", o autor tem por objetivo entender como a Coroa percebia os deslocamentos desses indivíduos para a região. Sua conclusão, baseada nos requerimentos de "migrantes voluntários" e nos pareceres do Conselho Ultramarino, é que essas jornadas eram vistas não só como forma de suprir a falta de mão-de-obra qualificada, mas também como uma maneira de povoar a regiáo.

O trabalho refuta as conclusóes que definem os degredados como indivíduos, em sua maioria, desregrados, preguiçosos e "criminosos da pior espécie", sustentando que essas características somente eram encontradas em parcela diminuta da populaçáo, cuja maioria era, de fato, formada por casais de colonos e por membros das expediçóes e tropas do reino. Chambouleyron destaca esse dado para argumentar que soldados e degredados eram indivíduos integrados à sociedade colonial, mesmo que por meio da fuga, e que as tropas e as famílias constituíam espaços sociais de interaçáo e negociação no sertão da Amazônia.

Os documentos históricos pesquisados revelam aspectos fundamentais para a compreensão das negociaçóes que envolviam o povoamento da Amazônia seiscentista. A análise mostra que, além dos casais açorianos, os irlandeses católicos também foram considerados como possíveis povoadores europeus das terras portuguesas. $\mathrm{O}$ autor demonstra a importância desse fato para a compreensão do contexto no qual o novo rei da casa de Bragança empenhava-se em ser reconhecido como soberano católico e interessava-se por "mais homens não hereges", com o objetivo de defender o território do Estado do Maranhão diante da ameaça dos holandeses, que já haviam invadido São Luis em 1640.

Sob a liderança do capitão Pedro Sweetman, muitos requerimentos de famílias irlandesas foram apreciadas pelo rei Dom João IV, seguindo um trâmite lento na corte portuguesa, mobilizando opositores, tanto em Lisboa, quanto no Maranhão colonial. Com o falecimento do capitão Sweetman, Guilherme Brum passou a comandar o projeto de migração dessas famílias para a Amazônia, cancelado definitivamente no ano de 1648, quando o rei suspendeu a licença dada a Brum. Além de representar um refúgio frente às perseguiçóes religiosas na Europa, a Amazônia atraía os casais irlandeses também pelas oportunidades que o comércio das drogas do sertáo oferecia. Sem deixar de reconhecer as tensóes que envolviam o processo de povoamento do Maranhão, Chambouleyron reconhece nas histórias dos capitães Sweetman, Brum e das famílias irlandesas, evidências da importância do povoamento da regiáo amazônica para a Coroa.

No capítulo segundo, "Capitanias, sesmarias e vilas", o autor analisa as estratégias adotadas pela Coroa para evitar o fracasso dos esforços de ocupação da Amazônia, destacando que o domínio da região ao longo do século XVII deve ser compreendido náo apenas a partir das açóes militares, sertanistas e missionárias, mas também de outras formas, como a sistematização da ocupação agrícola da terra e a fundação e acompanhamento de vilas e capitanias particulares. Seu argumento ganha um caráter crítico importante quando reconhecemos que a historiografia tradicional considera fundamental para o entendimento do domínio português apenas a defesa militar, a caça aos índios e as missóes. Além disso, muitos historiadores têm sustentado que foi somente a partir de 1750, graças à política pombalina, que Portugal passou a preocupar-se efetivamente com a ocupação e a exploração da região amazônica. Um dos méritos do trabalho de Chambouleyron, portanto, é demonstrar que, desde o século XVII, a Coroa já se preocupava com a ocupação e exploração da Amazônia. Nesse ponto, o autor apresenta uma bela análise sobre as tensóes que envolviam a doação de capitanias no Maranhão colonial, problematizando o conceito de territorialidade nesse contexto. O historiador deixa claro que o componente espacial é central e fundador dos conflitos nessa discussão - o objetivo não é apenas o poder sobre os índios, mas o poder sobre os índios em um determinado território - demonstrando as tensóes geradas pela superposição de poderes territoriais na região e suas projeçôes espaciais. 
Uma perspectiva inovadora apontada na obra é o estudo do processo de urbanização do Estado do Maranhão e Pará. Trata-se da ideia de que a distribuição de terras pode ter contribuído com adensamentos populacionais que, em algum momento, constituíram lugares muito povoados, devido a atividades agro-pastoris, o que levou à consolidação de núcleos populacionais no interior das propriedades agrícolas e possibilitou a formação de redes sociais. Isto permite um entendimento mais amplo do que aquele que aponta a urbanização da regiáo como conseqüência, apenas, da fundação das cidades de Belém e São Luís, das vilas, de algumas capitanias privadas e dos aldeamentos missionários. Chambouleyron não perde de vista o objetivo de analisar a ocupação atentando para a preocupação com o domínio do território. Ele chama atenção para o fato de que a distribuição da terra indica a geografia da ocupaçáo que consolidou, ao longo da primeira metade do século XVIII, o Estado do Maranhão e Pará.

A última parte da obra, "Açúcar, tabaco e o cultivo das drogas", apresenta de maneira clara de que forma a agricultura funcionou como ponto central na formatação da política de ocupação da Amazônia colonial. De acordo com Chambouleyron, a experiência agrícola no Estado do Brasil foi um "horizonte" para as capitanias do Estado do Maranhão, e não um "modelo”, como parte significativa da historiografia tende a pensar a relação entre as duas regiôes. Ele se debruça sobre as questóes que envolveram a economia do açúcar, relacionando a negociaçáo de africanos com o aumento de divisas para a Fazenda Real e o incremento do cultivo das canas e seus derivados, que ganhavam cada vez mais importância econômica na dinâmica interna do Estado do Maranhão. Já a produção de aguardente não teve o mesmo incentivo que o açúcar; ao contrário, era vista como problemática por induzir os moradores ao vício da bebida, muito embora se tornasse um produto cada vez mais importante para o domínio e a economia da regiáo.

A partir da análise de fontes que revelam as tensôes existentes entre os personagens envolvi- dos no cultivo das canas e seus derivados, o autor deixa claro que, para a Coroa, ao longo dos séculos XVII e XVIII, açúcar e aguardente eram termos que se excluíam. Um dos fatores importantes para o entendimento da forma de organização assumida pela sociedade no Estado do Maranhão Colonial é o papel central da produção de cachaça na região. Para Chambouleyron, essa é a chave que permite entender o posicionamento muitas vezes ambíguo da Coroa diante da aguardente, que tanto influenciou na relação entre os portugueses e os índios no sertão e nos engenhos.

Empregando argumentos consistentes, o autor apresenta os interesses da Coroa e as tensóes no desenvolvimento do cultivo dos produtos da terra, dos quais se destaca o cacau. A narrativa prende ainda mais a atenção ao demonstrar as mudanças de significados das drogas do sertão, a partir dos interesses da máquina burocrática e fiscal do Estado. Como exemplo destaca a distinção feita pela Coroa entre o "cacau cultivado" e o "cacau bravo", o primeiro gozando de maior status e conferindo direitos aos seus produtores, sinalizando a importância da agricultura para a política portuguesa de ocupação no Estado do Maranhão e Pará.

O historiador aponta, ainda, que o início do plantio de cacau na região partiu de interesses particulares e não institucionais. Considera que, neste assunto, a participação atribuída pela historiografia aos jesuítas foi excessiva. Sem perder de vista seus objetivos, Chambouleyron reforça o argumento de que a experiência da agricultura no Estado do Brasil foi um horizonte e não um modelo para o Estado do Maranhão, demonstrando que o cacau cultivado, o açúcar e o gado tinham o mesmo valor para a Coroa, revelando açóes políticas que procuravam se adaptar a diferentes realidades, rejeitando a conclusáo que aponta o fracasso da experiência colonial na Amazônia.

Ao longo do trabalho, o autor demonstra estar atento, também, aos fatores ambientais, ao comentar a importância das epidemias de bexigas em 1640 e 1690 e as catástrofes naturais ocorridas nas ilhas açorianas (erupçôes vulcânicas, incêndios e terremotos) que 
motivaram a migração em direção ao Estado do Maranhão colonial. Mas, a maneira como Chambouleyron constrói sua narrativa também nos permite considerar que ele poderia ter reconhecido o papel decisivo do meio ambiente de maneira mais clara. Embora destaque que a ocupação territorial agrícola das sesmarias do Estado do Maranhão e Pará teria levado em consideração o sistema fluvial da regiáo, o autor poderia ter avançado na discussão sobre a importância decisiva da natureza na ocupação da Amazônia no período colonial. Tal abordagem poderia revelar mais sobre a importância da domesticação de plantas no processo de ocupação e povoamento. Uma análise mais comprometida com as condiçóes ambientais talvez contribuísse para a constatação de que os incentivos da Coroa não fizeram do Maranháo um produtor de açúcar tão relevante quanto Pernambuco e a Bahia.

Isto, todavia, não diminui o mérito de Rafael Chambouleyron que, com esta obra, oferece ao leitor a oportunidade de conhecer a Amazônia seiscentista, não como uma regiáo abandonada ou "redescoberta" apenas pela interferência do Marquês de Pombal. Ao contrário, ele nos convida a interpretar os feitos pombalinos, a partir das açôes implementadas ainda no século XVII e na primeira metade do século XVIII. O estudo sugere vários temas de pesquisa, redimensiona o papel da Coroa, de seus representantes e das ordens religiosas no contexto do domínio colonial seiscentista, e reconhece a ação de outros personagens ignorados ou pouco percebidos pela historiografia. Por esses motivos, é possível afirmar que Povoamento, ocupação e agricultura na Amazônia Colonial (1640-1706) não contribui, apenas, para a compreensão do processo tenso de ocupação da terra na Amazônia, mas, também, da complexidade das condiçóes de vida que, até hoje, perduram nesta vasta regiáo do Brasil. 